\title{
Relation between renal function tests and a retrospective organic solvent exposure score
}

\author{
P HOTZ, ' J PILLIOD, ${ }^{1}$ D SÖDERSTRÖM, ' F REY, ${ }^{2}$ M A BOILLAT, ' H SAVOLAINEN \\ From the Institute of Occupational Health Sciences, ${ }^{1} 1005$ Lausanne, and Department of Endocrinology and \\ Clinical Biochemistry, ${ }^{2}$ Department of Internal Medicine, CHUV, 1011 Lausanne, Switzerland
}

ABSTRACT In case-control studies on glomerulonephritis and organic solvents several authors have assessed exposure to organic solvents with a score based on the self reported occupational history. The underlying principle is that all exposures can be weighted by an intensity factor and then added to get one number representative of lifetime exposure. As this score has hitherto not been validated the relation between this exposure score and kidney function tests in a population of workers with past or present exposure to organic solvents was examined. The results suggest that such relations do exist for the $\mathrm{N}$-acetyl- $\beta$-D-glucosaminidase (NAG) activity, erythrocyturia, and, perhaps, albuminuria but not for the protein creatinine ratio or for leucocyturia.

In their case-control studies on glomerulonephritis and organic solvents Bell et al ${ }^{1}$ and Ranskov et al ${ }^{2}$ assessed the exposure to organic solvents with an exposure score based on the occupational history. The relation between a quantitative exposure score and kidney function tests in a group of workers has not hitherto been examined.

This was accomplished in the present study by comparing the possible relation between this exposure score and clinical kidney function tests in a group of workers with definable past or present exposure to organic solvents. As Bell's exposure score is a summary measure of the organic solvent exposure which supervenes in different jobs, our main purpose was its validation by the comparison of the kidney function tests in different exposure score groups and not between different occupational categories.

Three hypotheses were examined: firstly, a search of correlation between exposure score and kidney function tests, secondly, the role of the duration of the exposure, and, finally, the possibility of a healthy worker effect.

\section{Subjects and methods}

Altogether 148 workers were examined as a part of a larger epidemiological study programme on the nephrotoxicity of organic solvents. Seven could not be examined because of holidays, leaving the job, refusal, foreign language, or organisational problems. The

Accepted 16 January 1989 calculation of the exposure score was not possible in one case. The $\mathrm{N}$-acetyl- $\beta$-D-glucosaminidase (NAG) activities are missing for 25 further workers because of technical problems at the beginning of the study.

To avoid a recall bias, subjects did not know that we were interested in the effects of organic solvents. The medical examination was always presented either as a periodic or preplacement medical examination or as a general evaluation of the possible occupational risks. All participants were working at the time of the examination and patients referred to us for possible occupational disease were not eligible.

Solvent exposure was assessed with the questions and the intensity factors proposed by Bell et al. ${ }^{1}$ Briefly, the exposure duration is assessed and then multiplied by an independently determined intensity factor. The resulting scores are then added to get the total lifetime score. The units are then years weighted by the exposure intensity factor.

The questionnaire suggested by Bell et al ${ }^{1}$ was used with some slight adaptations taking into account the characteristics of the different occupations with a potential solvent exposure in the study region. The intensity of solvent exposure was then graded as follows.

Heavy exposure (intensity factor 2) consisted of occupational house painting indoors, industrial spray painting without protection devices, carpet and floor covering cleaning with cleaning agents, floor laying or impregnating, or both, production of paint, production of glue, polyester resin application with heavy contact with styrene, ${ }^{3}$ glue sniffing, tank cleaning 
without protection devices, and paint stripping with organic solvents (if not already a painter).

Moderate exposure (intensity factor 1) consisted of non-occupational house painting indoors, spray painting with protective devices, industrial degreasing of metal, printing work, occupational gluing, anaesthetic work, dry cleaning, varnishing (if not already a painter), use of hair sprays, use of pesticides, and polyester resin application with low exposure to styrene.

Slight exposure (intensity factor 0.5 ) consisted of outdoor painting, motor repairing, handling of petrol fuels, tank cleaning with protective devices, hobby gluing, drawing with felt tipped pens, and exposure to exhaust fumes outdoors.

An open question that was coded blindly by an industrial hygienist asked for "other jobs with organic solvents." Care was taken to distinguish between solvent and water based cleaning agents, glues, and so on.

As the results of Bell et al, 'compatible in this regard with those of Ranskov et al, ${ }^{2}$ showed that nonoccupational exposures do not seem important and correspond to much smaller score values we simplified the calculations. The exposure durations were then expressed in years and months instead of hours. A month was defined as a minimal exposure time of one hour a workday or five hours a week or 20 hours a month. Shorter exposure times were considered as insignificant. Work breaks of more than two months were considered as unusual and the exposure duration was then proportionally reduced, as it was by part time jobs. The dates of beginning and ending jobs were precisely determined.

Written instructions were given to the examining doctors and all codings of the answers were reviewed by the same occupational health practitioner The exposure durations were recalculated by this second observer and differences of more than two months were not accepted.

The urinary cell counts were executed on uncentrifuged urine within one hour of micturition with a phase contrast microscope in a Bürker's cell. Two chambers of $0.9 \mathrm{~mm}^{3}$ were counted each time. Leucocytes and tubular cells were counted together according to Askergren. ${ }^{4}$ The difference between the two chamber counts was small (mean $=0.93$ cells for 15 counts with less than 11 erythrocytes, mean $=1 \cdot 5$ cells for 15 counts with less than 10 leucocytes). The interobserver error was greater for leucocytes (mean $=2.1$ cells for the same counts) than for erythrocytes (mean $=1$ cell per count).

NAG activity was assayed as described by Powell $e t$ $a l .{ }^{5}$ The mean intra-assay coefficient of variation was $2.5 \%(n=20)$. Creatinine in blood and urine was assayed by the Jaffé method (Boehringer Diagnostica,
Mannheim, Germany). Albuminuria was measured $b \overline{\bar{B}}$ radioimmunoassay (Pharmacia, Uppsala, Sweden) Shaw's index - that is, the protein: creatinine ratio in $\overline{\mathrm{B}}$ urine sample-is described as a semiquantitative assessment of the 24 hour excretion of protein. ${ }^{6}$ It wa. assayed according to Shaw et al with the methot described by Iwata et al. ${ }^{7}$ The mean intra-assa 5 coefficients of variation for 20 samples were $0.8 \%$ fo the protein and $0.9 \%$ for the urinary creatinin $\bar{\Phi}$ determinations.

The workers came fasting for examination and at their breakfast at the institute to reduce the individua $\bar{\Phi}$ variations in fluid intake. Total urine samples were collected on waking (urine 1) and after breakfast at the institute (urine 2). They were asked not to urinato between collections. Blood sampling was performe\& before breakfast. Assays of NAG, albuminuriais creatinine, and the cell counts were made on urine $2 . \circ$

As drugs or diseases could be important confound $\overrightarrow{-}$ ing factors, all subject who were regularly taking druggi at the time of the study or who had a clinical history with past or present diseases that could have some repercussion on the kidney or the urinary tract (the $s \sigma$ called patient group) were excluded in the second stes of the analyses. This patient group comprised 4\% people.

Hypertension means a diastolic blood pressure $\geqslant$ $96 \mathrm{~mm} \mathrm{Hg}$, a systolic blood pressure $\geqslant 141 \mathrm{~mm} \mathrm{Hg}_{0}$ 웡 both at the time of the clinical examination. Tweqves $(25 \%)$ of the patient group were hypertensive; the remaining eight hypertensive workers belong to group without kidney or urinary tract diseases (pasto present) and did not take drugs.

\section{Statistics}

The normality of the distributions were tested by the Kolmogorov-Smirnov test and a mathematical transformation was made when necessary. If this was nof successful non-parametric tests were used. One ang multiple way variance analysis, Kruskal-Wallis on@ way variance analysis, Kendall's or Pearson's correla? tions, and chi-squared tests were used. All calculations were done with the statistical package for socią sciences. $^{8}$

\section{Results}

The median exposure score was 5.3 units with a 90t percentile at 33.0 (range $0-72.6 ; n=140$ ). In Bell's units this corresponds to a median of 9240 , a mear ( \pm SEM) of 21612 (2328) (range: 0-127 776). Foo comparison Bell et al reported a mean value ( \pm SEM S $^{\circ}$ of 13 186(3716) (range 0-108 195) in the glomerulone phritis group $(n=50)$.

The exposure score was correlated with ag思 
$(\mathrm{r}=0.35 ; \mathrm{n}=140 ; \mathrm{p}: 0.000)$, as were exposure duration and age $(r=0.40 ; n=140 ; p: 0.000)$. In the study group duration of exposure explains the major proportion of the variance of the exposure score $\left(r^{2}=0 \cdot 767 ; n=140\right)$.

There is a weak but statistically significant correlation between raw exposure score and NAG activity $(\mathrm{r}=0.21 ; \mathrm{n}=114 ; \mathrm{p}: 0.001)$ or erythrocyturia $(r=0.12 ; n=136 ; p: 0.05)$. After exclusion of the patient group, the correlations between raw exposure score and NAG activity $(r=0.26 ; n=68 ; p: 0.002)$ or erythrocyturia $(r=0.20 ; n=84 ; p: 0.01)$ were slightly better but the explained variances were still small.

There was no correlation between raw exposure and

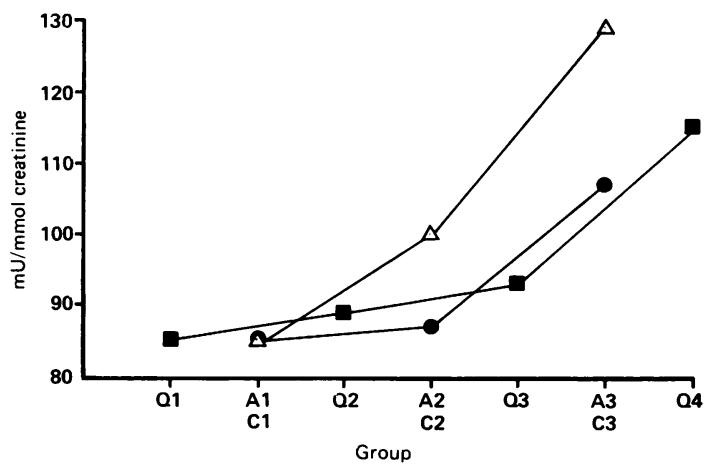

$N A G$ activity and exposure score. $\square$ Exposure score quartiles (groups Q1-Q4), ten year limit (groups A1-A3) (details: see text), $\triangle$ ten year limit and exposure intensity factor (groups C1-C3) (details: see text). Results calculated by variance analysis after correction for belonging to patient group and to "hypertensive group" (see methods). Factor exposure group is significant at $p 0.05$ for $Q 1-Q 4$ and 0.02 for $A 1-A 3$ and $C 1-C 3$. For comparison, effect of factor "hypertensive group" is significant at $p=0.03,0.03$, and 0.007 , respectively. Number is 110,110 , and 60 respectively. and albumin excretion rate, Shaw's index, or leucocyturia even after excluding the patient group.

As it is possible that the exposure score is a better estimate of exposure in a group than on an individual basis the whole group was subdivided into four quartiles $(\mathrm{Q} 1$ to $\mathrm{Q} 4$ in order of increasing exposure score). There is an increase in the NAG activity $(p=0.006 ; n=114)$ and in the number of workers with an erythrocyturia above the median as defined in their control group by Askergren et al $(\mathrm{p}=0.08 ; \mathrm{n}=$ 136). ${ }^{4}$

After exclusion of the so called patient group the significance levels are 0.01 in both cases $(n=68$ or 84 respectively) (tables 1 and 2, figure). A similar analysis was performed for leucocyturia but did not show a clear tendency. As there is no detailed publication about the normal distribution of erythrocyturia or leucocyturia in a healthy non-exposed worker group, a comparison with the normal ranges was not possible.

The same statistical analyses were carried out for albuminuria and Shaw's index with the upper limits of normal as cut off points, $20 \mu \mathrm{g} / \mathrm{min}^{9}$ for the albumin excretion rate or 127 for Shaw's index. ${ }^{6}$ The results did not show statistically significant tendencies.

It has been suggested that chronic organic mental disorders could appear after exposure to organic solvents for 10 years or more ${ }^{10}$ but it is not known whether this limit has any meaning for kidney function tests or whether the exposure intensity still has any influence beyond this ten year limit. Therefore, to examine the medical significance of this 10 year limit we built three subgroups with an exposure duration equal to 0 (group $A 1$ or controls), between 0.01 and 9.9 years (group A2), and equal to or greater than 10 years (group A3). NAG activity and the number of people with an erythrocyturia above the median were greater in group A3 than in the other subgroups (table 3, figure). Table 1 shows that the exposure score is greater in this subgroup as well. A similar trend was

Table 1 Age and exposure to organic solvent

Subgroups by

10 year limit and

Exposure score quartiles 10 year limit $\quad \begin{aligned} & \text { To year limit and } \\ & \text { intensity factor }\end{aligned}$

\begin{tabular}{|c|c|c|c|c|c|c|c|c|c|c|}
\hline \multirow[b]{2}{*}{ Variables } & & & \\
\hline & $Q 1$ & $Q 2$ & $Q 3$ & $Q 4$ & $A I$ & $A 2$ & $A 3$ & $C 1$ & $C 2$ & $C 3$ \\
\hline $\begin{array}{l}\text { Age }(y): \\
\overline{\mathbf{x}} \\
\text { SD } \\
\text { No }\end{array}$ & $\begin{array}{l}33 \cdot 0 \\
11 \cdot 4 \\
38\end{array}$ & $\begin{array}{l}28 \cdot 6 \\
8 \cdot 6 \\
32\end{array}$ & $\begin{array}{l}39 \cdot 0 \\
11 \cdot 1 \\
35\end{array}$ & $\begin{array}{l}46 \cdot 5 \\
9 \cdot 8 \\
35\end{array}$ & $\begin{array}{l}33 \cdot 3 \\
11 \cdot 8 \\
32\end{array}$ & $\begin{array}{c}30 \cdot 1 \\
9 \cdot 5 \\
53\end{array}$ & $\begin{array}{c}45 \cdot 5 \\
9 \cdot 4 \\
55\end{array}$ & $\begin{array}{l}33 \cdot 3 \\
11 \cdot 8 \\
32\end{array}$ & $\begin{array}{l}48 \cdot 55 \\
9.9 \\
24\end{array}$ & $\begin{array}{c}43 \cdot 3 \\
9 \cdot 4 \\
17\end{array}$ \\
\hline $\begin{array}{l}\text { Exposure durati } \\
\text { Median/No } \\
\text { Range }\end{array}$ & $\begin{array}{l}\text { (y): } \\
0.0 / 38 \\
0.0-0.1\end{array}$ & $\begin{array}{l}1 \cdot 8 / 32 \\
0 \cdot 1-8 \cdot 4\end{array}$ & $\begin{array}{c}12 \cdot 8 / 35 \\
3 \cdot 0-29 \cdot 0\end{array}$ & $\begin{array}{l}23 \cdot 0 / 35 \\
10 \cdot 3-44 \cdot 0\end{array}$ & $\begin{array}{l}0.0 / 32 \\
0.0-0.0\end{array}$ & $\begin{array}{l}3 \cdot 0 / 53 \\
0 \cdot 1-9 \cdot 8\end{array}$ & $\begin{array}{l}21 \cdot 2 / 55 \\
10 \cdot 3-44 \cdot 0\end{array}$ & $\begin{array}{l}0.0 / 32 \\
0.0-0.0\end{array}$ & $\begin{array}{l}22 \cdot 1 / 24 \\
13 \cdot 2-44 \cdot 0\end{array}$ & $\begin{array}{l}16 \cdot 5 / 17 \\
10 \cdot 3-36 \cdot 3\end{array}$ \\
\hline $\begin{array}{l}\text { Exposure score: } \\
\text { Median/No } \\
\text { Range }\end{array}$ & $\begin{array}{l}0 \cdot 0 / 38 \\
0.0-0 \cdot 1\end{array}$ & $\begin{array}{l}1 \cdot 8 / 32 \\
0 \cdot 2 / 5 \cdot 2\end{array}$ & $\begin{array}{l}11 \cdot 5 / 35 \\
5 \cdot 3 / 20 \cdot 2\end{array}$ & $\begin{array}{l}30 \cdot 4 / 35 \\
20 \cdot 6 / 72 \cdot 6\end{array}$ & $\begin{array}{l}0.0 / 32 \\
0.0-0.0\end{array}$ & $\begin{array}{l}3 \cdot 3 / 53 \\
0.05-17 \cdot 6\end{array}$ & $\begin{array}{l}22 \cdot 8 / 55 \\
5 \cdot 5-72 \cdot 6\end{array}$ & $\begin{array}{l}0.0 / 32 \\
0.0-0.0\end{array}$ & $\begin{array}{l}22 \cdot 1 / 24 \\
13 \cdot 2-44 \cdot 0\end{array}$ & $\begin{array}{l}33 \cdot 0 / 17 \\
20 \cdot 6-72 \cdot 6\end{array}$ \\
\hline
\end{tabular}


Table 2 Erythrocyturia and exposure score quartiles

\begin{tabular}{llllr}
\hline & \multicolumn{5}{l}{ Subgroups* } \\
\cline { 2 - 5 } No of cases with values & $Q 1$ & $Q 2$ & $Q 3$ & $Q 4$ \\
\hline Below the mediant $\dagger$ & 19 & 13 & 10 & 9 \\
Above the median $\dagger$ & 17 & 18 & 24 & 26 \\
\hline
\end{tabular}

*Difference statistically significant at $p=0.08$ and after excluding the patient group at $p=0.01(n=84)$ (chi-squared test).

tAs defined in his control group by Askergren.

Table 3 Erythrocyturia and exposure of duration

\begin{tabular}{llll}
\hline & \multicolumn{3}{l}{ Subgroups* } \\
\cline { 2 - 4 } No of cases with values & $A 1$ & $A 2$ & $A 3$ \\
\hline Below the mediant $\dagger$ & 17 & 19 & 15 \\
Above the median $\dagger$ & 13 & 32 & 40
\end{tabular}

*Difference statistically significant at $p=0.03$ and after excluding the patient group at $p=0.07(n=84)$ (chi-squared test).

†As defined in his control group by Askergren. ${ }^{4}$

observed for the albuminuria but not for Shaw's index or for leucocyturia. Excluding the patient group did not alter the results.

The same variables were then compared between three other subgroups: the first with no exposure at all, the second with all workers who stayed 10 years or more in the same exposure category, and the third with all other workers. The purpose was to see whether people who stayed a longer time in the same exposure category behave in a way different from workers with one or several short durations of exposure. The results were identical.

To test the respective roles of the chronic exposure and of the intensity factor we built three homogeneous subgroups. The first (C1) comprised workers with no exposure.

The two others comprised either printers (intensity factor 1) (group C2) or floor layers (intensity factor 2) (group C3). In both groups the duration of exposure in this industry branch is equal to or greater than 10 years. It may be seen in table 1 that exposure duration and score diverge. Group C2 has a longer exposure time but a lower score than group C3 (there were unfortunately not enough people with the same occupation in the low exposure category for building a third homogeneous group).

Again, NAG activity and the number of workers with an erythrocyturia above the median are highest in the group with the greatest exposure score (table 4, figure). Exclusion of the patient group did not alter the trend but for erythrocyturia the numbers were too small for a valid chi-squared test. Testing the exposed groups taken together against the control group,
Table 4 Erythrocyturia, 10 year duration of exposure score $\overline{\bar{z}}$

\begin{tabular}{|c|c|c|c|}
\hline \multirow[b]{2}{*}{ No of cases with values } & \multicolumn{3}{|c|}{ Subgroups* } \\
\hline & $C 1$ & $C 2$ & C3 \\
\hline $\begin{array}{l}\text { Below the mediant } \\
\text { Above the median } t\end{array}$ & $\begin{array}{l}17(14) \\
13(11)\end{array}$ & $\begin{array}{r}7(3) \\
17(9)\end{array}$ & $\begin{array}{r}2(0) \\
15(6)\end{array}$ \\
\hline
\end{tabular}

*Difference statistically significant at $p=0.006$; after excluding the patient group chi-squared is no more valid (because of too many cells with expected frequencies $<5$ ). The numbers after this exclusion are given in parentheses. The comparison of $\mathrm{Cl}$ againstu $\mathrm{C} 2+\mathrm{C} 3$ taken together is significant at $\mathrm{p}=0.02(\mathrm{n}=43)$ aftef $^{\prime}$ excluding the patient group.

†As defined in his control group by Askergren."

however, did reach statistical significance, even afteo excluding the patient group $(p=0.02 ; n=43)$.

The albumin excretion rates are compatible with this trend but the number of pathological values is small (1/24 in the non-exposed and 2/16 in the exposed groups, after exclusion of the patient group) which precludes statistical examination. Leucocyturia andr Shaw's index were again not clearly related to the exposure score.

As diuresis could alter our results the varianç analysis for NAG activity was made with the uncorrected enzyme activity and by taking diuresis as an additional independent variable. The effect of thळ exposure score remains evident but the explained variance increased to $41 \%$. If the erythrocyte excret rates are used instead of the erythrocyte concentiations similar trends are obtained.

Finally, it should be mentioned that the number. workers with an erythrocyturia above the median is not greater in the group with a raised blood pressure $(p=0.50 ; n=136)$. After excluding the patien $B$ group, there is no relation between NAG activity of erythrocyturia and age either in the whole group or in the control group $(p \geqslant 0.22)$.

The serum creatinine concentrations were comparz able in all subgroups.

\section{Discussion}

The interpretation of the relation between exposures score and kidney function tests is made difficult by the presence of confounding factors such as hypertensiono and kidney or urinary tract disease. As the prevalence of these disturbances increases with age which is itselfo associated with the exposure score, the influence of such confounding factors should be ruled out.

A significant role of age is unlikely for erythrocyturia $^{1112}$ or albuminuria. ${ }^{13-15}$ For NAG activity the age factor seems to play a part in one study ${ }^{16}$ but was considered as insignificant or weak by other workers. ${ }^{17-19}$

In this study we found no statistically significante 
association between age and NAG activity, increased albumin excretion rate, or erythrocyturia above the median either in all workers or in the controls after excluding the patient group. Furthermore, the results observed in subgroups $\mathrm{Cl}-\mathrm{C} 3$ cannot be explained by a hypothetical influence of age. Therefore, it seems unlikely that age has biased our results.

Taking account of blood pressure and clinical history in the analysis did not alter our results which can therefore not be ascribed merely to an association between age, higher exposure score, and pathological states.

Some NAG activities were lost at the beginning of the study but the missing cases came from the same plants as the valid cases. Furthermore, the loss was due to technical problems and not to selection. Consequently a bias seems unlikely.

Evidently, our sample is not representative of the most frequent jobs with exposure to organic solvents because printers and floor layers are overrepresented. These results should not be generalised before more extensive studies have been completed.

Obviously no unifying mechanism for the kidney effects can be presented in populations with such differing exposure conditions. Transient microalbuminuria is associated, for example, with generalised traumatic capillary permeability but this recedes within hours of the event. ${ }^{20}$ On the other hand, microalbuminuria seems to be associated with an increased risk of diabetic nephropathy ${ }^{9}$ and of vascular disease in non-diabetic subjects. ${ }^{13}$ There is also an association between increased NAG activity and kidney disease. ${ }^{16-19}$

The renal changes permitting erythrocyturia are not clear. No consistent pathological alterations have been found in glomerular basement membrane in idiopathic microscopic haematuria. ${ }^{21}$ A distinction between glomerular and non-glomerular erythrocytes may shed some light on this equation.

In conclusion, we found a connection between the retrospective organic solvent exposure score as assessed with a slightly modified Bell's questionnaire and kidney function tests in a working population. We think that this is an interesting finding in view of the results of those authors who observed an association between this exposure score and the relative risk of glomerulonephritis.

We thank Mrs M Badan and Miss A Bertalot for the careful typing of the manuscript and Dr J Holtz for his help.

\section{References}

1 Bell GM, Gordon ACH, Lee P, et al. Proliferative glomerulonephritis and exposure to organic solvents. Nephron 1985;40: 161-5.

2 Ravnskov U, Forsberg B, Skerfving S. Glomerulonephritis and exposure to organic solvents. A case-control study. Acta Med Scand 1979;205:575-9.

3 Guillemin MP, Bauer D, Martin B, Marazzi A. Human exposure to styrene. IV. Industrial hygiene investigations and biological monitoring in the polyester industry. Int Arch Occup Environ Health 1982;51:139-50.

4 Askergren A. Studies on kidney function in subjects exposed to organic solvents. III. Excretion of cells in the urine. Acta Med Scand 1981;210:103-6.

5 Powell SC, Scaro J, Wilson E, Shihabi ZK. Assay of urinary Nacetyl- $\beta$-glucosaminidase in a centrifugal analyser. Clin Chem 1983;29:1717-9.

6 Shaw AB, Risdon P, Lewis-Jackson J. Protein creatinine index and albustix in assessment of proteinuria. $\mathrm{Br}$ Med $J$ 1983;287: 929-32.

7 Iwata J, Nishikaze 0 . New micro-turbidimetric method for determination of protein in cerebrospinal fluid and urine. Clin Chem 1979;25:1317-9.

8 SPSS-XTM user's guide. Chicago: SPSS Inc, 1988.

9 Mogensen CE. Microalbuminuria as a predictor of clinical diabetic nephropathy. Kidney Int 1987;31:673-89.

10 Gadeholt H. Quantitative estimation of cells in urine. An evaluation of the addis count. Acta Med Scand 1968;183:369-74.

11 Freni SC, Dalderup LM, Oudegeest JJ, Wensveen N. Erythrocyturia, smoking, and occupation. J Clin Pathol 1977;30: $341-4$.

12 Yudkin JS, Forrest RD, Jackson CA. Microalbuminuria as predictor of vascular disease in non-diabetic subjects. Lancet 1988;ii:530-3.

13 Askergren A, Allgen LG, Karlsson C, Lundberg I, Nyberg E. Studies on kidney function in subjects exposed to organic solvents. I. Excretion of albumin and $\beta$-2-microglobulin in the urine. Acta Med Scand 1981;209:479-83.

14 Tucker SM, Boyd PJR, Thompson AE, Price RG. Automated assay of $\mathrm{N}$-acetyl- $\beta$-glucosaminidase in normal and pathological human urine. Clin Chim Acta 1975;52:333-9.

15 Watts GF, Morris RW, Khan K, Polak A. Urinary albumin excretion in healthy adult subjects: reference values and some factors affecting their interpretation. Clin Chim Acta 1988; 172:191-8.

16 Wellwood JM, Ellis BG, Price RG, Hammond K, Thompson AE, Jones NF. Urinary $\mathrm{N}$-acetyl- $\beta$-D-glucosaminidase activities in patients with renal disease. $B r$ Med J 1975;iii:408-11.

17 Verschoor M, Wibowo A, Herber R, van Hemmen J, Zielhuis R. Influence of occupational low-level lead exposure on renal parameters. Am J Ind Med 1987;12:341-51.

18 Kunin CM, Chesney RW, Craig WA, England AC, DeAngelis C. Enzymuria as a marker of renal injury and disease: studies of $\mathrm{N}$ acetyl- $\beta$-glucosaminidase in the general population and in patients with renal disease. Pediatrics 1978;62:751-60.

19 Shearman CP, Gosling P. Microalbuminuria and vascular permeability. Lancet 1988;ii:906-7.

20 Fujigaki Y, Nagase M, Kobayashi S, Honda N, Muranaka Y. Alterations of glomerular basement membrane relevant to haematuria. Virchows Arch (Pathol Anat) 1988;413:159-65.

21 World Health Organisation. Regional Office for Europe/Nordic Council of Ministers. Chronic effects of organic solvents on the central nervous system and diagnostic criteria. Report. Joint meeting, 10-14 June 1985, Copenhagen, Copenhagen/Oslo: WHO Regional Office for Europe/Nordic Council of Ministers, 1985:1-273. (Environmental health series 5.) 